\title{
The Dynamics of General Insurance Sector in India - Growth and Performance Perspective
}

\author{
Kattamuri Satish
}

\begin{abstract}
Life is full of risks and uncertainties. In fact risk is everywhere. Even when you ride a bike to the nearest shop in the street, there is a risk. One must protect himself or herself from this risk. The solution is insurance. Broadly it is two types i.e. life insurance and non-life insurance (general insurance). In this paper we discuss about only general insurance. General insurance helps in securing ourselves and things we value like homes, cars, bikes or any other property from any kind of mishap whether it is big or small. General insurance protect insured property from fire accidents, floods, earthquakes, storms, thefts, travel accidents/mishaps or any other kind of calamity, even from the cost incurred against us from legal action depending upon the type of policy selected by the insurer. From the post liberalization scenario, general insurance in India is growing rapidly. The reasons behind its spectacular growth are allowing private companies to enter into Indian market, low insurance premium, TPAs (Third Party Administrators), Fast and immediate settlement of insurance claims, Innovative general insurance policies, discounts in insurance products, increasing awareness among people, more distribution channels etc. The other side of the coin is, public sector insurance companies are facing cut throat completion from private insurance companies as they offer wide variety of policies at a low premium. Due to this few general insurance companies are closed and few are forced to come out with same polices and services. Ultimately the performance of public sector general insurance companies also enhanced with the competitive moves by private players. On the other hand, customers are also exposed to new trends in the insurance market. Insurance Regulatory and Development Authority (IRDA) is the apex body in India to monitor the activities of insurance companies. It has laid down standard terms and conditions to general insurance companies and also given scope for personal accidental life insurance policies. IRDA has taken all the measures to improve the performance of general insurance companies as it is one of the fast growing areas in Indian economy. General insurance companies under public sector are facing lot of challenges from private players and to with stand in the completion, even they have improved a lot in their quality of service in multiple facets like decreasing the premium, quick settlement in claims etc. In a nut shell, general insurance business is contributing significantly to Gross Domestic Product (GDP).
\end{abstract}

Key words: IRDA, general insurance, claims, premiums, risks, public and private sector general insurance companies.

\section{INTRODUCTION}

General insurance is not far behind of life insurance.

Revised Manuscript Received on December 30, 2019.

* Correspondence Author

Dr. Kattamuri Satish, Professor, Avanthi PG and Research Academy, Hyderabad-501512 (Telanagana) India. E-mail ID: s1.kattamuri@gmail.com

(C) The Authors. Published by Blue Eyes Intelligence Engineering and Sciences Publication (BEIESP). This is an open access article under the CC BY-NC-ND license (http://creativecommons.org/licenses/by-nc-nd/4.0/)
Now a day's people are more cautious about their assets also, they are taking all possible measures to protect it from any kind of mishap; there general insurance comes into picture. Therefore general insurance is equally important with life insurance. In simple words general insurance provides a blanket of financial protection for the insured assets from natural calamities, ill health, any kind of medical emergency, accidents or misfortunes etc. Any kind of non life insurance policy comes under general insurance. Basically there are four broad categories general insurance they are number one health insurance, number two motor insurance, number three travel insurance and number four home insurance and of course there are many more categories but these four are note worthy.

Recent Developments in General Insurance Sector in India: Insurance is a booming sector in India. It is the best target market for many foreign insurance players. As per the latest report of India Brand Equity Foundation (IBEF) released in September 2019, Indian insurance industry is estimated to reach 280 billion US dollars (Approximately 20142500000000 rupees) by 2020 which is an unprecedented growth, but still it is very low as its contribution to GDP is just $3.69 \%$. The following are the noteworthy developments in the general insurance sector. HDFC Ergo has acquired Apollo Munich Health Insurance for rupees 2,600 crores. It has also started 'E@Secure' to offer cyber insurance policies for individuals in the month of September 2018. Flipkart, one of the major players in Indian electronic commerce market has entered into insurance business in association with Bajaj Allianz to offer mobile insurance in the month of October 2018.In the year 2017, the total insurance business in India is around rupees 434.3 billion through public issues along with ten merger and acquisition deals worth rupees 64,81,18,31,700. Bombay Stock Exchange (BSE) is about to enter in a joint venture with Ebix Inc to build a robust insurance distribution network within the country through unique and new distribution platform. Keeping the growing scenario of general insurance in mind, an attempt is made on critical evaluation of performance of selected general insurance companies in public as well as private sector in India.

\section{REVIEW OF LITERATURE}

Jawahar Babu (2010): This study focuses on the overall factors influencing the claims settlements in motor insurance provided by third party agents especially. Majority of the claims are decided by court of law which causes unusual delay in settlement. 
This is also due to the increase in motor accidents. To precise, this study precisely focused on claim settlement procedure.

K. Rajender et.al. (2012): In this study, the researchers focused on investment patterns of selected general insurance companies. An in depth analysis is made on both term-wise and security-wise parameters. On the whole, this study focused on how the money collected from insurance premiums should be invested, so that the portfolios can yield more returns.

Saroji Hiremath (2013): In this study the researcher focused on emerging trends and challenges faced by general insurance companies in India particularly from multinational insurance companies, diversified and customized patterns in their service. Despite the general insurance business in India is growing by increasing players in the same domain because India is huge market and the scope for increasing is also high.
S. Anoop Kumar (2014): In this study, the researcher focuses on process adopted by general insurance companies in ascertaining the loss by considering motor claims connected with parts and miscellaneous. The researcher has opined that all the parts which are made by use of composite material fall under the definition of the other parts for the purpose of applying depreciation.

Bhardwaj Geeta et.al. (2015): This study focused on frauds and challenges faced in health insurance. The researcher acknowledged the procedure to overcome from fraud successfully. The business should adopt a top down strategy the effect the risk actually has on their business. It investigates the number of fraud cases in India and observed that $15 \%$ of total claims and the types of claims are opportunistic fraudsters, repeat fraudsters, organized fraudsters. Fraud from the point of insurer as well as insured identified use commonly assessed fraud.

\section{CONCEPTUAL MODEL}

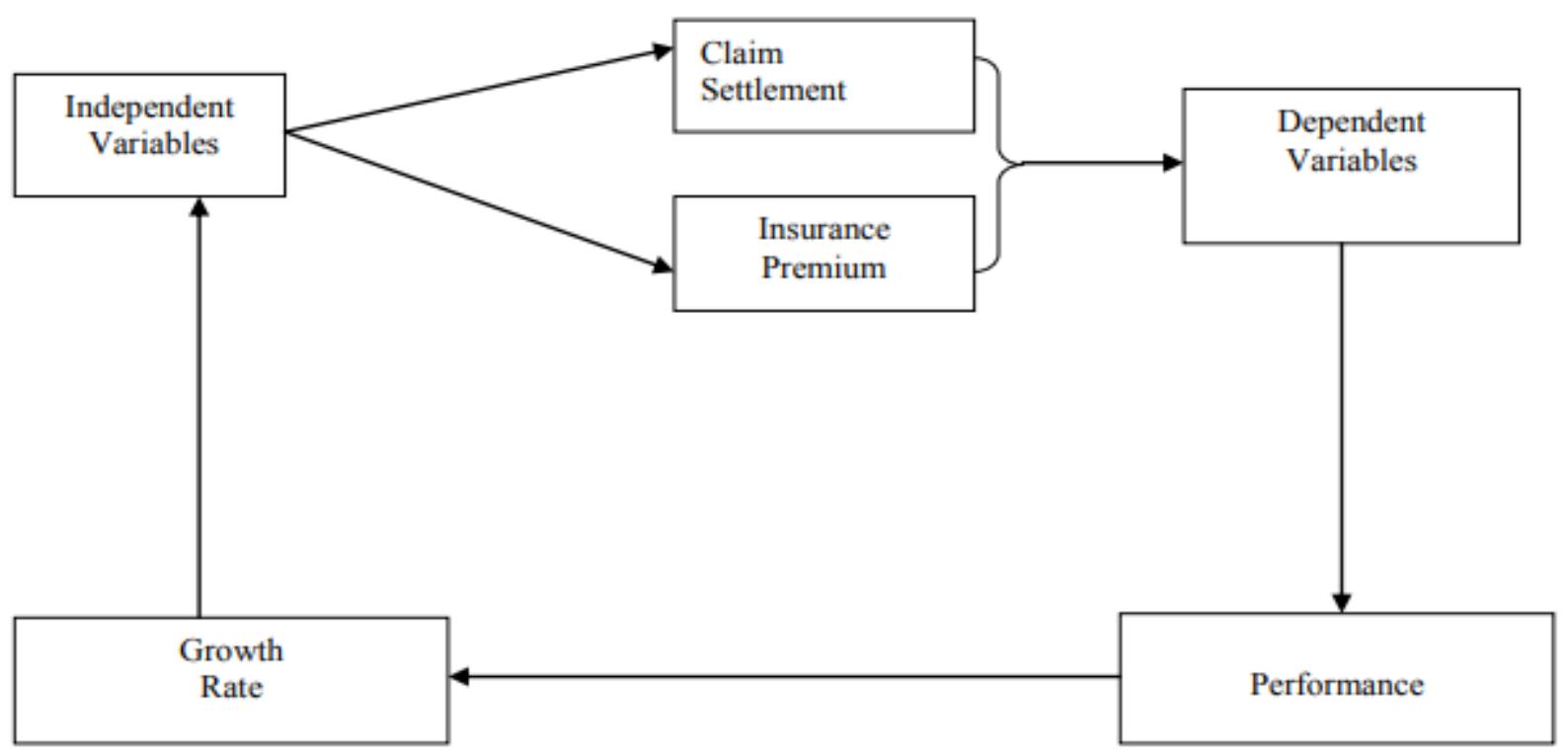

\section{NEED FOR THE STUDY}

This Paper primarily directed towards analyzing the general insurance premium patterns and claim settlement procedure among various public and private player in India. Secondarily, it focuses on critical evaluation of performance of premiums and claim trend among selected general insurance companies in India.

\section{OBJECTIVES OF THE STUDY}

The following objectives have been undertaken for this study. 1. To study about insurance premium patterns of selected general insurance companies

2. To know the insurance claim settlement procedure among selected general insurance companies

3. To evaluate the performance general insurance companies especially from the view point of premium amount and claim settlement procedure

\section{METHODOLOGY}

The methodology must specify the procedures or methods of collecting data and proposed tools for analyzing the collected data. It should give answer to the following questions.

1. What are the various sources of data and how it should be collected i.e. must specify the type of instrument to be used in obtaining data

2. What should be the optimum sample size so that results could be more reliable?

For this study, the data is collected mainly from secondary source i.e. monthly reports and journals of Insurance Regulatory Development Authority (IRDA), Other journals in the field of insurance, published books, annual reports on insurance topics and of course from selected general insurance companies websites. 
The sample size is 10 general insurance companies out of which four are from public sector and six are from private sector. The period of study is 2010 to 2018 i.e. eight years.

The 4 general insurance companies selected under public sector are

1. $\quad$ National Insurance Company Limited

2. $\quad$ New India Assurance Company Limited

3. $\quad$ Oriental Insurance Company Limited

4. $\quad$ United India Insurance Company Limited

The 6 general insurance companies selected under private sector are

1. Bajaj Allianz General Insurance

\section{A. Percentage Analysis}

Table-1: Trend Analysis of Insurance Premium Collected

\begin{tabular}{|l|c|c|}
\hline Year & Total Premium (in Rs.) & Growth Percentage (\%) \\
\hline 2010 & 21235.43 & - \\
\hline 2011 & 24111.73 & 13.55 \\
\hline 2012 & 28398.34 & 17.35 \\
\hline 2013 & 35171.43 & 24.29 \\
\hline 2014 & 41823.44 & 18.97 \\
\hline 2015 & 47018.23 & 12.42 \\
\hline 2016 & 52567.43 & 12.95 \\
\hline 2017 & 58456.42 & 13.91 \\
\hline 2018 & 60329.41 & 13.42 \\
\hline \multicolumn{2}{|c|}{ Average Growth: $13.85 \%$} \\
\hline
\end{tabular}

*Source: IRDA Annual Reports 2010-18

Interpretation: The above table describes the total insurance premium collected by both public and private sector general insurance companies. It is observed that there is a significant growth in the percentage of premium collected from 2011
2. ICICI Lombard General Insurance

3. Royal Sundaram Allianz Insurance

4. IFFCO Tokyo General Insurance

5. Reliance General Insurance

6. Tata AIG General Insurance

\section{RESULTS AND DISCUSSION}

The following statistical tools are used to analyze the data collected. They are trend analysis, regression analysis, measures of central tendency, percentages and averages. To support the analysis diagrams, tables are used wherever it is necessary.

Fig.-1: Graphical Presentation of growth in premium collected.

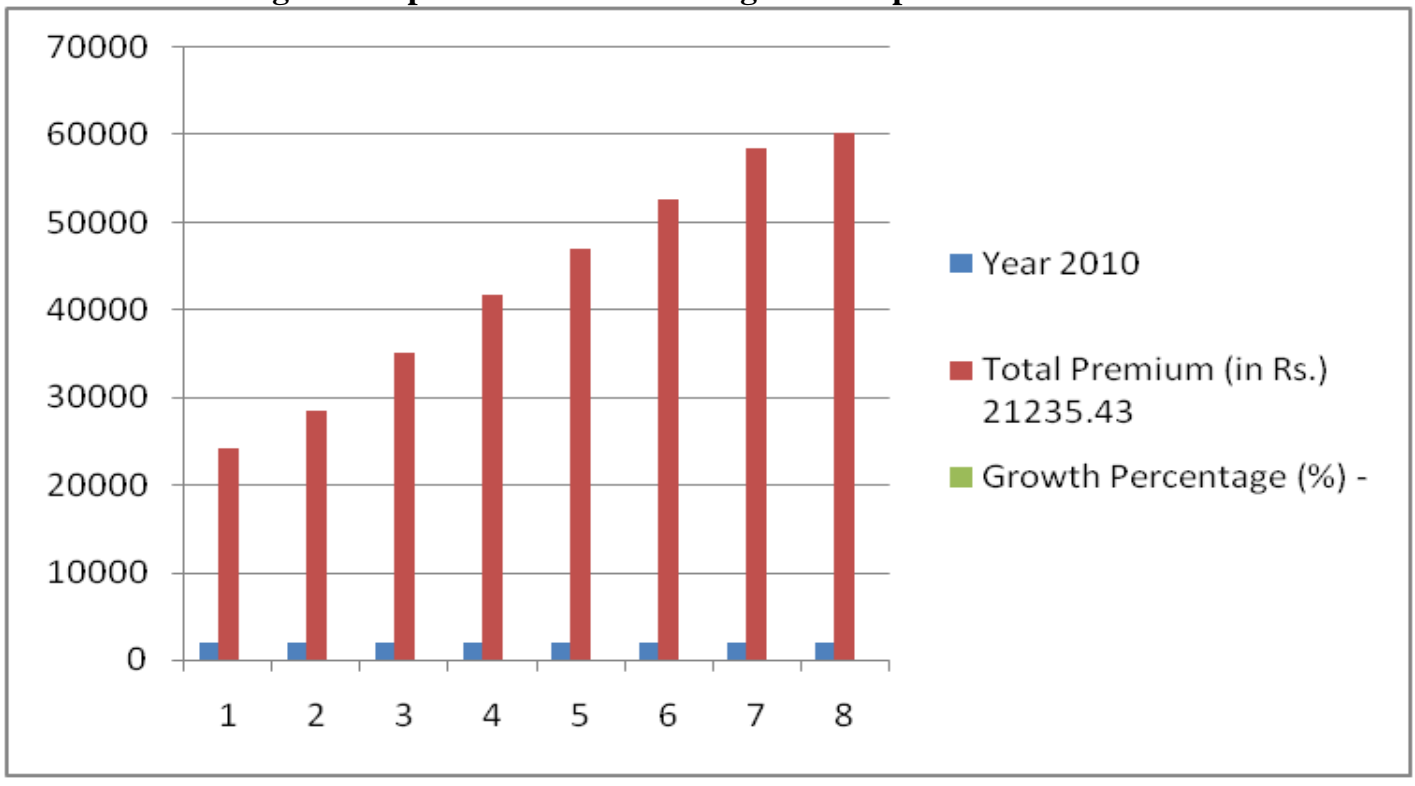

Retrieval Number: B3261129219/2019@BEIESP

DOI: 10.35940/ijeat.B3261.129219

Journal Website: www.ijeat.org
(13.55\%) to 2013 (24.29\%) later on it is decreased (18.97\%). However there is a substantial growth in amount collected. The following figure explains the trend in the growth of insurance premium collected. 
The Dynamics of General Insurance Sector in India - Growth and Performance Perspective

Table-2: Trend Analysis of Insurance Claims Settled

\begin{tabular}{|l|l|l|}
\hline Year & Claims Settled (in Rs.) & Growth Percentage (\%) \\
\hline 2010 & 19123.06 & - \\
\hline 2011 & 20618.24 & 11.32 \\
\hline 2012 & 24785.76 & 14.31 \\
\hline 2013 & 29875.32 & 18.21 \\
\hline 2014 & 34652.14 & 23.65 \\
\hline 2015 & 36874.49 & 9.42 \\
\hline 2016 & 39743.75 & 12.91 \\
\hline 2017 & 45123.85 & 16.32 \\
\hline 2018 & 51834.21 & 19.87 \\
\hline Average Growth: $14.43 \%$ & \\
\hline
\end{tabular}

*Source: IRDA Annual Reports 2010-18

Interpretation: Similar to the analysis made in table-1, here also we could observe the growing trend in the claims settlements by both public and private sector general insurance companies. It is noticed that there is a significant growth in the percentage of claims settlements from 2011
(11.32\%) to 2014 (23.65\%) later on it is decreased (9.42\%). However there is a huge growth in settlements of claims by insurance companies. The following figure explains the trend in the growth of claims settled.

Fig.-2: Graphical Presentation of Claims Settled

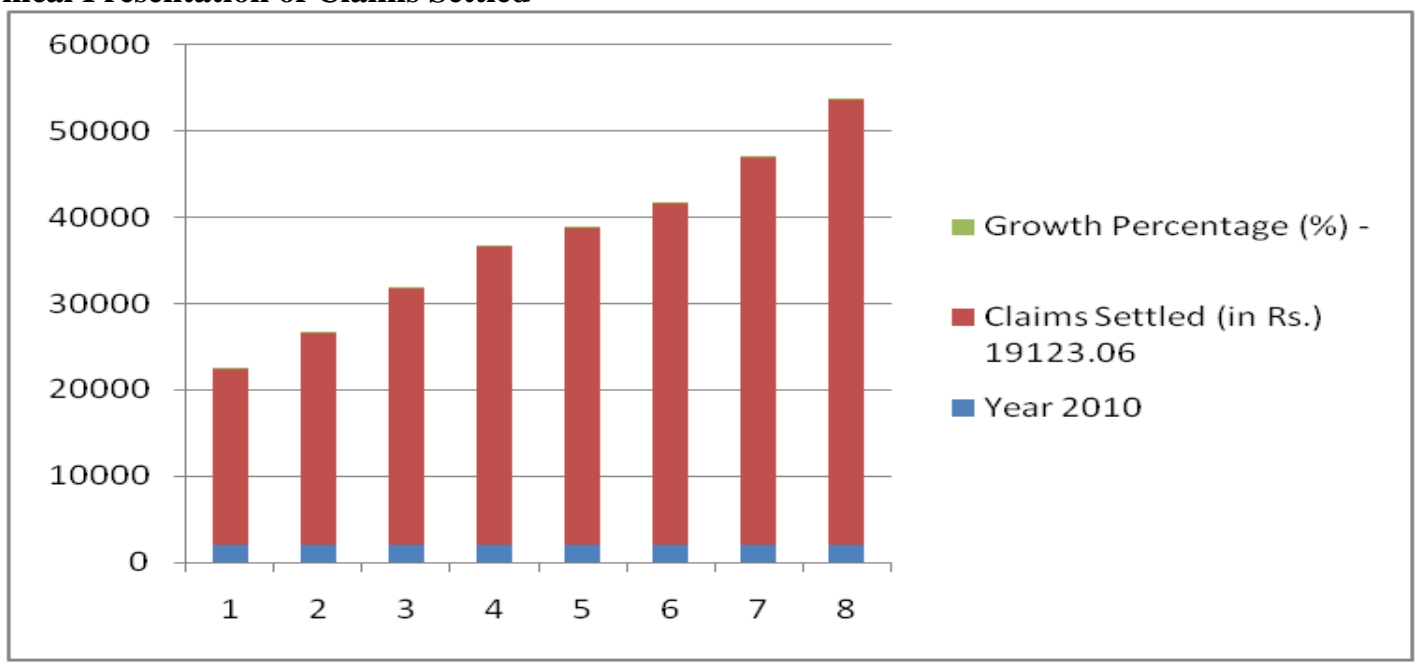

\section{B. Regression Analysis}

The simple regression equation is given by $Y_{t}=\alpha+\beta X_{t}+t_{i}$

Where $Y t=$ Claims settled from 2010-2018

$\mathrm{X}_{\mathrm{t}}=$ Insurance premium Collected from 2010-2018

$t_{i}=$ Error term or residual error

Table-3: Total Premium Collected and Claims Settled

\begin{tabular}{|c|c|c|}
\hline Year & Total Premium (in Rs.) & Claims Settled (in Rs.) \\
\hline 2010 & 21235.43 & 19123.06 \\
\hline 2011 & 24111.73 & 20618.24 \\
\hline 2012 & 28398.34 & 24785.76 \\
\hline 2013 & 35171.43 & 29875.32 \\
\hline 2014 & 41823.44 & 34652.14 \\
\hline 2015 & 47018.23 & 36874.49 \\
\hline 2016 & 52567.43 & 39743.75 \\
\hline 2017 & 58456.42 & 45123.85 \\
\hline
\end{tabular}

Retrieval Number: B3261129219/2019@BEIESP

DOI: 10.35940/ijeat.B3261.129219

Journal Website: www.ijeat.org
Published By:

Blue Eyes Intelligence Engineering

\& Sciences Publication

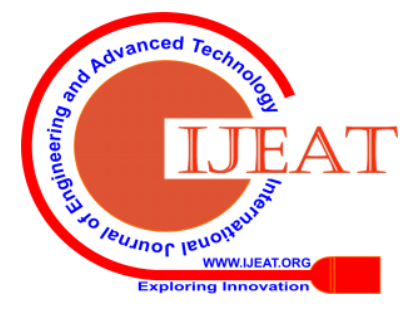


*Source: Consolidation of Table 1 and Table 2

Table-4: SPSS analysis of Regression Output

\begin{tabular}{|c|c|c|c|c|}
\hline \multirow{2}{*}{ Model } & \multicolumn{2}{|c|}{ Unstandardized Coefficients } & Standardized Coefficients & \multirow{2}{*}{$\mathrm{t}$} \\
\cline { 2 - 5 } & Beta & Standard error & Beta & \\
\hline Constant & 1328.692 & 1080.032 & - & 1.230 \\
\hline Premium & 0.810 & 0.29 & 0.995 & 0.254 \\
\hline
\end{tabular}

*LOS- Level of Significance at 5\%

The projected regression equation after substituting the values is given by $\mathbf{Y t}=\mathbf{1 3 2 8 . 7}+\mathbf{0 . 8 1 0} \mathrm{X}_{\mathbf{t}}+\mathbf{t}_{\mathbf{i}}$

Interpretation: In simple words for each unit of one unit of increase in insurance premium, 0.81 times settlement has to be paid towards claims disbursement.

\section{CONCLUSION}

This study destined to evaluate the performance of selected general insurance companies. It is observed that public sector general insurance companies have to adopt new and innovative polices to give momentum to the growth so that they can compete with private players. The development in general insurance business in India, so far, is only the good start still it has to reach $90 \%$ of the population in India. It is an evergreen and emerging market for insurance companies if they focus. As people are also getting aware of insurance products and services, the regulatory body i.e. Insurance regulatory Development Authority (IRDA) must focus on safeguarding the people's interest by laying down standard polices to be followed by both public and private sector general insurance companies.

\section{LIMITATIONS}

The couple of limitations of this study are following.

1. This study is completely based on secondary source of data of selected general insurance companies in India.

2. Evaluations of performance of selected insurance companies are only based two variables on insurance premium amount and claim settlement procedure. Other variable factors are ignored.

\section{REFERENCES}

1. Insurance Principles and Practice M.N. Mishra, S.Chand \& Company Ltd. Ram Nagar, New Delhi, 2004. p.3.

2. Gobi S. and Parthasarathy R, - Selected health insurance schemes in India, Asian Journal of Research in Social Sciences and Humanities, Year : 2011, Volume : 1, Issue : 4, pp.31-40.

3. Michielsen, Joris; Criel, Bart; Devadasan, Narayanan; Soors, Werner; Wouters, Edwin; Meulemans, Herman, Can health insurance improve access to quality care for the Indian poor?, International Journal for Quality in Health Care, Volume 23, Number 4, 13 August 2011 , pp. 471-486(16).

4. Rohit Kumar, K. Rangarajan and Nagarajan Ranganathan, - Health Insurance in India-A Study of Provider's Perceptions in Delhi \& the NCR, Journal of Health Management September 2011 vol. 13 no. 3 259-277.

5. Sharma Aparajita, -Managerial Competencies For Middle-level Managers of General Insurance Sector In India, A Journal of Decision Making, Year : 2011, Volume : 11, Issue : 1, pp.27-39.

6. Tarek Abd Elhamid Ahmed Taha, Yusnidah Ibrahim and Mohd Sobri Minai, - Forecasting general insurance loss reserves in Egypt, African
Journal of Business Management Vol. 5(22), pp. 8961-8970, 30 September, 2011.

7. Pascale Turquet, - Health insurance system financing reforms in the Netherlands, Germany and France: Repercussions for coverage and redistribution?, International Social Security Review, Volume 65, Issue 1, pages 29-51, January-March 2012

8. Srivastava, Samir K. and Ray, Avishek , Benchmarking Indian General Insurance Firms (October 8, 2011). Benchmarking: an International Journal, 2012. Available at SSRN: http://ssrn.com/ abstract=1968871.

9. Sukumar Vellakkal,, Financial Protection in Health Insurance Schemes: A Comparative Analysis of Mediclaim Policy and CHAT Scheme in India, Journal of Health Management March 2012 vol. 14 no. 1 13-25.

10. Vipin Saxena, Deepa Raj, and Vishal Verma, -Vehicle Insurance Policy System through UML, International Journal of Computer and Electrical Engineering, Vol.4, No.1, January 2012.

11. Chennappa, D. (2006), "Result of Liberalized India's Insurance Sector: Challenges and Opportunities", The ICFAI Journal of Risk and Insurance. Vol. III, No.3, July, pp. 65-75.

12. Easwaran, P. S. (2007), "Growth of Indian Insurance Industry after opening up to Private Sector", The Insurance Times, November, pp. 19-21.

13. Ramana, B. V. (2007), "Insurance Regulator: The Emerging Challenges", Insurance Chronicle, October, pp. 17-23.

14. Sinha, R. P. (2007), "Productivity and Efficiency of Indian General Insurance Industry", The ICFAI Journal of Risk and Insurance, Vol. IV, No.2, April, pp. 33-43.

\section{AUTHORS PROFILE}

Dr. Kattamuri Satish

Professor Avanthi PG and Research Academy, Hyderabad-501512, Telanagana, India. mail ID: s1.kattamuri@gmail.com Contact No.: +91-9492746097 